\title{
An Ethical Evaluation Process for Mediators: A Preliminary Exploration of Factors Which Impact Ethical Decision-Making
}

\author{
Bobette Wolski
}

\begin{abstract}
Ethical decision-making by mediators is, of necessity, contextual in nature. When mediators are confronted with an ethical dilemma such that they must choose between two or more 'right' or 'good' but contradictory courses of action, they must take numerous case-specific factors into account in arriving at a decision that they can justify. This article identifies some of the factors which mediators might take into account in deciding what is the 'ethically fitting' course to be followed. It provides detailed discussion of three factors which impact ethical decision-making by mediators. They are: the objectives and values given priority in mediation; the approaches or models of mediation chosen by a mediator; and the standards of conduct to which mediators are subject. In discussing these factors, attention is given to the debate concerning the appropriateness of evaluative mediation. Attention is also drawn to the difficulty involved in drafting standards of conduct for mediators. The focus of the discussion about mediator standards of conduct is upon Australia's National Mediator Accreditation Scheme Practice Standards. As with most mediator standards, inevitably they provide no more than a set of core principles or values which form a framework for ethical decision-making by mediators.
\end{abstract}

\section{INTRODUCTION}

As mediation practice has become more commonplace, such that it is now an integral part of the civil justice system in Australia (and elsewhere), ${ }^{1}$ attention has turned to the issues of regulation, and quality assurance, of the conduct of mediators. The task of drafting standards of conduct for any profession is difficult. The task of drafting standards for mediators is especially difficult, for a number of reasons such as: there is no single definition of 'mediation' that would meet with universal acceptance; ${ }^{2}$ mediation is (intended to be) a flexible process; and it may take different

1 For an account of the legislative position in each Australian jurisdiction, see David Spencer and Samantha Hardy, Dispute Resolution in Australia: Cases, Commentary and Materials (Lawbook Co, Thomson Reuters, 3rd ed, 2014) 707-712. See also Bobette Wolski, 'On Mediation, Legal Representatives and Advocates' (2015) 38(1) University of New South Wales Law Journal 5, 5.

2 In this article, mediation is defined in broad terms as a process in which an acceptable third party, the mediator, undertakes a range of activities to assist the parties involved in a dispute or a potential deal to negotiate an agreement. The activities undertaken by the mediator fall short of imposing a decision upon 
forms and serve a range of different and sometimes conflicting objectives and values; and mediators come from diverse professional backgrounds. Despite the difficulty, several sets of standards and guidelines of conduct have been developed. ${ }^{3}$ Not surprisingly however, most standards of conduct for mediators are general in nature providing no more than a set of core principles or values which form a framework for ethical decision-making.

In this article, the term 'ethics' is 'loosely defined as the question of what is 'right' or 'good' behaviour from a moral ... point of view'. ${ }^{4}$ Fundamentally, ethics is all about values as Preston notes by observing that in a preliminary way we may regard ethics as the study which arises from the human capacity to choose among values'. ${ }^{5}$ Values are the principles or beliefs to which we attribute worth. ${ }^{6}$ An ethical dilemma arises when there is a '[c]hoice of competing values (ideas of goodness)' 7 which suggests 'a variety of alternative and contradictory courses of action'. 8

There are two significant strands of moral philosophy evident in the history of ethics, 'moral universalism' (ethical problems can be solved 'in terms of universals', ${ }^{9}$ for example, all killing is wrong) and 'applied ethics' (a specific context frames an ethical problem - killing may be justified in some circumstances). ${ }^{10}$ This article favours the second strand. When mediators (and other human beings) are confronted with an ethical dilemma such that they have to make a choice between contradictory courses of action, they may be influenced in their decision-making by a number of different approaches to ethical reasoning ${ }^{11}$ including a rule or duty-based approach ("what does the rule/standard prescribe in these circumstances?'), social contract ethics ('what is the custom and norm on this issue within the mediation community?'), end-result ethics ('what

the parties: see Bobette Wolski, 'Culture, Society and Mediation in China and the West' (1996-97) 3 Commercial Dispute Resolution Journal 97, 98-99.

3 See, for example, the standards developed in connection with the National Mediator Accreditation System (NMAS), Revised NMAS, Part III - Practice Standards, effective 1 July 2015 <www.msb.org.au/sites/default/files/documents/ NMAS\%201\%20July\%202015.pdf> (NMAS Practice Standards). In addition to the NMAS Practice Standards, see the standards and guidelines mentioned below, n 61-63, 66 .

4 Donald Nicolson, 'Mapping Professional Legal Ethics: The Form and Focus of the Codes' (1998) 1(1) Legal Ethics 51, 54.

$5 \quad$ Noel Preston, Understanding Ethics (Federation Press, 3rd ed, 2007) 7.

6 Ibid 16.

7 Joseph Fletcher, 'Situation Ethics, Law and Watergate' (1975-1976) 6 Cumberland Law Review 35, 55.

8 Christine Parker and Adrian Evans, Inside Lawyers' Ethics (Cambridge University Press, 2nd ed, 2014) 16.

9 See Geoffrey C Hazard Jr, 'Law Practice and the Limits of Moral Philosophy' in Deborah Rhode (ed), Ethics in Practice: Lawyers' Roles, Responsibilities and Regulation (Oxford University Press, 2000) 75, 76.

10 Ibid.

11 See Roy J Lewicki, Bruce Barry and David M Saunders, Negotiation (McGrawHill, 6th ed, 2010) 256-264 for a discussion of four different approaches to ethical reasoning. 
are the consequences of the action and does the end justify the means'?), care-based ethics ('what is best for the parties' relationships with each other and other parties?') ${ }^{12}$ and personalistic ethics ('what feels right on the basis of my own conscious and moral standards?'). A mediator might have an inclination towards one or other of these approaches but the approaches are not mutually exclusive and can be applied in combination. A mediator might defer to a different combination each time he or she mediates. ${ }^{13}$

Regardless of the approach(es) to ethical decision-making that influence a mediator, and whether or not the mediator is conscious of doing so, he or she will use an ethical evaluation process when confronted with an ethical dilemma. An ethical evaluation process has been described as 'a process for working out in concrete and particular circumstances what is the ethically fitting course to be followed'. ${ }^{14}$ It 'involves a balance of conflicting values and a search for the best solution in a specific set of circumstances'. ${ }^{15}$

The aim of this article is to identify some of the factors which mediators might take into account in deciding what is the 'ethically fitting' course to be followed when confronted with an ethical dilemma. Important determinants of the decisions arrived at by mediators include (this list is not intended to be exhaustive): ${ }^{16}$

- The mediator's own personality and style.

- The training received by the mediator and the original professional orientation of the mediator.

- The model of mediation (or combination of models) preferred and used by the mediator (which in turn may depend on the values and objectives given priority).

- The interests of the mediator.

- The context in which the mediation takes place, for example, whether it takes place within the context of public policy, commerce, employment or the family.

- The characteristics of the parties, for example, whether they are sophisticated professionals or relatively unsophisticated 'first-timers' in a family law matter.

12 The concept of an 'ethic of care' is usually credited to Carol Gilligan: see Carol Gilligan, In a Different Voice: Psychological Theory and Women's Development (Harvard University Press, 1982).

13 Margaret Ann Wilkinson, Christa Walker and Peter Mercer, 'Do Codes of Ethics Actually Shape Legal Practice?' (2000) 45 McGill Law Journal 645, 651.

14 Preston, above n 5, 65.

15 Omer Shapira, 'Joining Forces in Search for Answers: The Use of Therapeutic Jurisprudence in the Realm of Mediation Ethics' (2008) 8(2) Pepperdine Dispute Resolution Law Journal 243, 255.

16 Laurence Boulle, Mediation: Principles, Process, Practice (LexisNexis Butterworths, 3rd ed, 2011) 267-268; Bobette Wolski, 'Mediator Settlement Strategies: Winning Friends and Influencing People' (2001) 12(4) Australasian Dispute Resolution Journal 248, 256-257. 
- The nature of the relationship between the parties and in particular, whether or not they are relatively equal in power.

- The nature of the dispute, for example, whether it is high or low conflict.

- The terms of any formal agreement to mediate and of any applicable standards of conduct.

- The institutional or agency setting in which the mediation takes place. Mediation will differ depending on whether it is private or court-based; and it will differ between service providers.

- '[T]he proximity of the dispute to the law'17 and the existence (or nonexistence) of a judicial alternative if mediation fails to resolve the dispute.

- The time pressure operating on the parties.

- The likely outcomes of the mediation and the effect on the parties themselves and other affected parties.

The article examines three of the factors that impact ethical decisionmaking by mediators. In part two of the article, the objectives and values claimed for mediation are identified. These inform the approaches or model(s) of mediation chosen by a mediator. The most well-known models of mediation are considered in more depth in part three. The debate concerning the appropriateness of evaluative mediation is canvassed. An attempt is made to find a unifying theme within the diversity of mediation practice - that theme is the self-determination of the parties involved in the mediation. Part four identifies the principal duties imposed on mediators by applicable standards of conduct. The focus of this article is the National Mediator Accreditation Scheme Practice Standards (NMAS Practice Standards). In conclusion, it is suggested that mediator decision-making is, of necessity, contextual in nature - when mediators are confronted with an ethical dilemma, they must take numerous casespecific factors into account in arriving at a decision that they can justify.

\section{Objectives and Values of Mediation}

Amongst the objectives claimed for mediation are the following: ${ }^{18}$

- Dispute resolution according to standards agreed by the parties (they may defer to legal standards or to any other standards they consider fair and appropriate) using a process considered by the parties to be fair. ${ }^{19}$

17 Laurence Boulle, Mediation: Principles, Process, Practice (LexisNexis Butterworths, 1996) 25.

18 In the context of this article, objectives (or goals) are the things we strive to achieve through the use of mediation (which is not to say that these objectives are all achieved). On the objectives of mediation, see Boulle, Mediation, 3rd ed, above n 16, 91-97.

19 National Alternative Dispute Resolution Advisory Council (NADRAC), Report to the Commonwealth Attorney-General, A Framework for ADR Standards (April 2001) 13. 
- Satisfaction of individual interests or needs.

- Recognition (that is, a greater openness to, and acceptance of, the other party to the dispute).$^{20}$

- Mutually acceptable outcomes which are also fair and stable.

- Outcomes which represent the best alternatives available and maximisation of joint gains.

- Enhanced relationships (or at least, minimisation of damage to relationships).

- Increased access to a 'higher quality justice"21 (that is, justice that is responsive to individual needs and reflective of the preferences of the parties). ${ }^{22}$

- Efficiency and effectiveness. ${ }^{23}$

Mediation is premised on a range of values including: ${ }^{24}$

- Party participation and autonomy.

- Process fairness.

- Self-determination (promoting 'subsidiary values of responsibility for choices and dignity of individuals' $)^{25}$ and empowerment, giving the parties an increased sense of their own personal efficacy.

- Consensuality of outcome.

- Efficiency.

Some of the objectives and values claimed for mediation may conflict. ${ }^{26}$ When mediation first emerged in the community environment in the 1970s it offered an opportunity to minimise state intervention in interpersonal disputes. However over time mediation has been taken up by courts and tribunals in all relevant jurisdictions. Parties may be compelled to attend mediation, sometimes as a prerequisite to commencing proceedings. ${ }^{27}$ Mediation offers a way to alleviate congestion and delay in the court

20 Robert A Baruch Bush and Joseph P Folger, The Promise of Mediation: Responding to Conflict Through Empowerment and Recognition (Jossey-Bass, 1994) 89-91.

21 Robert A Baruch Bush, 'Efficiency and Protection, or Empowerment and Recognition?: The Mediator's Role and Ethical Standards in Mediation' (1989) 41 Florida Law Review 253, 257. As to whether or not we are achieving that objective, see Mary Anne Noone and Lola Akin Ojelabi, 'Ensuring Access to Justice in Mediation within the Civil Justice System' (2014) 40(2) Monash University Law Review 528-563.

22 Robert P Burns, 'Some Ethical Issues Surrounding Mediation' (2001) 70 Fordham Law Review 691, 701.

23 See Boulle, Mediation, 3rd ed, above n 16, 92-95 for a discussion of the meaning of these two terms.

24 Ibid 62-90 for a general discussion of the values claimed for mediation.

25 Boulle, Mediation, 1996 ed, above n 17, 65.

26 For a discussion about the 'contradictory' and conflicting objectives of mediation, see Ulrich Boettger, 'Efficiency Versus Party Empowerment - Against A GoodFaith Requirement In Mandatory Mediation' (2004) 23(1) Review of Litigation 1, 8-12.

27 See Wolski, above $\mathrm{n} 1$ and references cited therein. For a discussion about the reforms as a result of which mediation was incorporated into the civil justice system, see Bobette Wolski, 'Reform of the Civil Justice System 25 Years Past: (In)Adequate Responses from Law Schools and Professional Associations? (and 
system. The courts emphasise the objectives and values of settlement, speed, efficiency of the judicial system, rational allocation of judicial resources and greater access 'to justice' at lower costs. ${ }^{28}$ These objectives and values are not necessarily compatible with those of self-determination, empowerment, recognition and satisfaction of individual interests.

The priority afforded to various objectives and values differs depending on whether one is looking at the issue from the perspective of society, individual disputants, the service provider, and the individual mediator - all of whom may select some objectives and values over others. ${ }^{29}$ The choice of intervention made by individual mediators is particularly important reflecting as it does his or her 'conception of the values and goals of the mediation process itself'.$^{30}$ For this reason, Boulle concludes that ' $[\mathrm{u}]$ ltimately ... mediation values are realised in its application by individual practitioners in particular cases. ${ }^{31}$

\section{Emerging Models of Mediation}

Over time a number of different styles or models of mediation have been identified. These models 'differ from each other in the way they describe the purpose of mediation [and in the values to which priority is given] and the role of mediators'.$^{32}$ Boulle identifies four paradigm models - the settlement, facilitative, therapeutic and evaluative models. ${ }^{33}$ The four models highlight the diversity of mediation practice and the fact that the objectives and values of mediation ultimately depend on the model favoured by the mediator ${ }^{34}$ (and where the parties have a choice, upon the model preferred by the parties). They also highlight the lack of consensus by mediation practitioners and academics over the 'proper' objectives, values and practice of mediation. The models are discussed in more detail below.

Mediators in the settlement model of mediation tend to favour positional negotiation. Their interventions are aimed at moving the

How Best to Change the Behaviour of Lawyers)' (2011) 40(1) Common Law World Review 40.

28 For discussion of the objectives sought to be achieved by courts in using mediation, see Nancy A Welsh, 'The Thinning Vision of Self-Determination in Court-Connected Mediation: The Inevitable Price of Institutionalization?' (2001) 6 Harvard Negotiation Law Review 1, 22-23. See also Noone and Akin Ojelabi, above $\mathrm{n} 21$.

29 This is reflected in the work undertaken by NADRAC in developing ADR Standards: NADRAC, 'A Framework for ADR Standards Report', above n 19, 13.

30 Julie Macfarlane, 'Mediating Ethically: The Limits of Codes of Conduct and the Potential of a Reflective Practice Model' (2002) 40(1) Osgoode Hall Law Journal 49,51 .

31 Boulle, Mediation, 3rd ed, above n 16, 90.

32 Shapira, above n 15, 244.

33 Boulle, Mediation, 3rd ed, above n 16, 43-47.

34 For a discussion of the linkages to be made between the intended objectives of mediation and the model preferred by a mediator, see Macfarlane, above n 30 , 51. 
parties from fixed positions to a point of compromise. The main objective of settlement mediation is ' $[t]$ o encourage incremental bargaining towards compromise, at a "mid" point between parties' original positional demands'. ${ }^{35}$ Mediators and parties using this model are concerned with the values of 'compromise, effectiveness and efficiency. ${ }^{36}$ Values such as party participation and empowerment are not a priority or even necessary elements of the process used.

In the facilitative model, mediator interventions are aimed at improving the processes of communication and negotiation between the parties. The objective of facilitative mediation is ' $[\mathrm{t}] \mathrm{o}$ avoid positions and negotiate in terms of parties' personal and commercial needs and interests instead of legal rights and duties'. ${ }^{37}$ In this model, participants will favour interest-based or integrative negotiation, party participation and active listening to search for solutions which satisfy the parties' legal and nonlegal interests. As for values, Boulle notes that this model stresses 'the relative priority of interests over rights and the need to acknowledge and validate views and emotions'. ${ }^{38}$

As suggested by its label, mediators in the therapeutic model use professional therapeutic techniques and focus on relationship issues. In this model, reaching agreement is not necessarily the primary concern. The therapeutic model of mediation is aimed at dealing 'with underlying causes of parties' problems, with a view to improving their relationship, through recognition and empowerment, as a basis for resolution of the dispute'. ${ }^{39}$ Its values are empowerment for self, that is, giving the parties an increased sense of their own personal efficacy with respect to process, goals, resources and decision-making, and recognition of the other that is, creating a greater openness to and acceptance of the person seated on the other side of the table. ${ }^{40}$

In the evaluative model, mediators may give the parties legal advice ${ }^{41}$ and offer them an opinion as to the range of outcomes likely to be handed down by a court. The objective in this model of mediation is ' $\mathrm{t}$ ] $\mathrm{o}$ reach a settlement according to the legal (or other) rights and entitlements of the parties and within the anticipated range of court, tribunal or industry outcomes'. ${ }^{42}$ Evaluative mediation tends to be the province of high profile lawyers and other substantive experts who develop their own opinion about preferable settlement options and may try to influence the parties to accept them. ${ }^{43}$ Boulle observes that evaluative mediation 'assumes

35 Boulle, Mediation, 3rd ed, above n 16, 44.

36 Ibid 63.

37 Ibid 44.

38 Ibid 63.

39 Ibid 44.

40 Bush and Folger, above n 20, 85-91.

41 On the differences between legal advice and legal information, see Law and Justice Foundation of New South Wales, definitions of 'legal information' and 'legal advice', Gateways to the Law (2001) <www.lawfoundation.net.au/report/gateways>.

42 Boulle, Mediation, 3rd ed, above n 16, 44.

43 Ibid. 
the value of the mediator's experience and expertise in guiding parties to accept normative or standard outcomes'. ${ }^{44}$ It honours the values of efficiency and protection of rights. ${ }^{45}$

These styles or paradigm models are not distinct alternatives to one another. Mediators may use techniques associated with two, three or four models in a single mediation. ${ }^{46}$ This type of mediator conduct is apparently the norm, at least in relation to 'civil legal disputes'. ${ }^{47}$

Now we turn to the issue of self-determination. Despite the diversity of mediation practice, there is wide agreement that party self-determination is central to all models of mediation. ${ }^{48}$ It has been called the driving value behind mediation ${ }^{49}$ and its 'most fundamental principle'.$^{50}$ Alfini claims that self-determination is 'the one value that distinguishes mediation from other dispute resolution processes'. ${ }^{51}$

Standards of conduct for mediators also emphasise the importance of party self-determination. The NMAS Practice Standards include 'self-determination' as a component of the definition of mediation. ${ }^{52}$ Unfortunately, the NMAS Practice Standards do not define the term 'self-determination'. Its meaning is to be found, however, in s 7.4 of the Standards, which provides that mediators 'must support participants to reach agreements freely, voluntarily, without undue influence and on the basis of informed consent'. Further clarification of the meaning of self-determination can be found in other standards of conduct and in the work of various scholars. ${ }^{53}$ For instance, the Model Standards of Conduct for Mediators in the US define self-determination as 'the act of coming to a voluntary, uncoerced decision in which each party makes free and informed choices as to process and outcome'. ${ }^{54}$

44 Laurence Boulle, Mediation: Principles, Process, Practice (LexisNexis Butterworths, 2nd ed, 2005) 60.

45 For discussion of the evaluative model, see Samuel J Imperati, 'Mediator Practice Models: the Intersection of Ethics and Stylistic Practices in Mediation' (1997) 33(3) Willamette Law Review 703, 711-712.

46 Boulle, Mediation, 3rd ed, above n 16, 43.

47 Dwight Golann, 'Variations in Mediation: How - and Why - Legal Mediators Change Styles in the Course of a Case' (2000) Journal of Dispute Resolution 41, 42.

48 Jacqueline M Nolan-Haley, 'Lawyers, Clients, and Mediation' (1997-1998) 73(5) Notre Dame Law Review 1369, 1374.

49 Lela Porter Love, 'Mediation: The Romantic Days Continue' (1997) 38 South Texas Law Review 735, 739.

50 James J Alfini, 'Mediation as a Calling: Addressing the Disconnect Between Mediation Ethics and the Practices of Lawyer Mediators' (2007-2008) 49 South Texas Law Review 829, 830.

51 Ibid 831.

52 See the definition of mediation contained in s 2.2 of the NMAS Practice Standards, above $\mathrm{n} 3$.

53 See, for example, Donald T Weckstein, 'In Praise of Party Empowerment - and of Mediator Activism' (1997) 33 Willamette Law Review 501, 530.

54 Discussed in Laura E Weidner, 'Model Standards of Conduct for Mediators' (20052006) 21(2) Ohio State Journal on Dispute Resolution 547, 556. 
While all stakeholders in the mediation community agree that parties must have sufficient information (including information as to the available alternatives to an offered settlement) to make an informed decision, ${ }^{55}$ there is some disagreement regarding the appropriate methods of informing them. In particular, disagreement centres on what role the mediator should play in informing the parties. This disagreement lies at the heart of the debate about the appropriateness of evaluative mediation.

Some authors oppose the concept (and practice) of evaluative mediation. They maintain that mediation should be solely facilitative in nature. ${ }^{56}$ Other authors are in favour of evaluative mediation principally on the grounds that it can further the objective and value of self-determination ${ }^{57}$ and that it "may be necessary in some cases to serve other acknowledged values, such as fairness, balance of power, needs and interests, and full disclosure'. ${ }^{58}$

The NMAS Practice Standards seek to find middle ground, providing that a mediator should refer the parties to external sources of information and advice where necessary ${ }^{59}$ and limiting the circumstances in which a mediator might use a 'blended process' model such as evaluative mediation to those in which the participants give clear consent to its use; the mediator holds the requisite knowledge and experience, has professional registration (for instance, a mediator who gives legal advice must be qualified to practise law) and indemnity insurance. ${ }^{60}$

The NMAS Practice Standards are discussed in more detail in the next part of the article.

\section{Standards of Conduct for Mediators}

Ethical standards and guidelines for mediators have been developed by their professional organisations (such as, for lawyers, their peak national body $^{61}$ and some State and Territory law societies and bar associations). ${ }^{62}$ Additionally, relevant mediator standards have been developed by a number of other ADR practitioner accreditation organisations whose membership is not restricted to lawyers or to any other professional group. ${ }^{63}$ Perhaps the most important set of standards in Australia is that

$55 \quad$ Weckstein, above n 53, 530.

56 Kimberlee K Kovach and Lela P Love, “Evaluative” Mediation is an Oxymoron' (1996) 14(3) Alternatives to High Cost of Litigation 31.

57 Weckstein, above n 53, 503.

58 Robert B Moberly, 'Mediator Gag Rules: Is It Ethical For Mediators to Evaluate or Advise?' (1997) 38 South Texas Law Review 669, 678 (citations omitted).

59 NMAS Practice Standards, above n 3, ss 3.2(f), 8.5.

60 NMAS Practice Standards, above n 3, ss 8.5, 10.2.

61 See Law Council of Australia (LCA), Ethical Guidelines for Mediators (at August 2011).

62 See, for example, Law Society of New South Wales, Guidelines for Legal Practitioners who Act as Mediators (at December 2012).

63 See, for example, Resolution Institute Code of Ethics (at 1 January 2015). In the US, see the American Arbitration Association, the American Bar Association 
promulgated in connection with the National Mediator Accreditation System (NMAS) which commenced operation in Australia on 1 January 2008. The NMAS is an industry-based system which relies on voluntary compliance by mediator organisations (known as Recognised Mediator Accreditation Bodies or RMABs) that agree to accredit mediators in accordance with stipulated NMAS Standards. Two sets of standards were promulgated in connection with the NMAS, Approval Standards which specify the qualifications and training requirements for accreditation under the system ${ }^{64}$ and Practice Standards which specify 'the minimum practice and competency requirements of a NMAS accredited mediator'. ${ }^{65}$ The Standards were recently revised, with the revisions taking effect from 1 July 2015. The Standards do not purport to be the sole source of regulation for mediators, providing that mediators must still adhere to the ethical code of their original professional association, and also allowing that additional standards might apply when a person practises 'as a mediator in other contexts, such as hybrid, blended or statutory environments'. ${ }^{66}$

Most standards define the mediator's role in general terms as one in which he or she 'facilitates the resolution of a dispute by promoting uncoerced agreement by the parties to the dispute'. ${ }^{67}$ Under the NMAS Practice Standards mediators are tasked with assisting the parties 'to make their own decisions in relation to disputes, conflicts or differences among them' 68 by facilitating communication, promoting understanding, and helping the parties to negotiate an agreement. ${ }^{69}$

The standards point to the existence of at least seven central overlapping duties owed by mediators to the parties to a mediation (these duties are also founded in contract, that is, the agreement to mediate in the case of private mediations; in tort; and possibly in equity relying on a fiduciary

(Section of Dispute Resolution) and the Association for Conflict Resolution, Joint Standards, Model Standards of Conduct for Mediators (2005) (Model Standards of Conduct for Mediators).

64 Revised NMAS, Part II - Approval Standards, s 1.2(a), effective 1 July 2015 $<$ www.msb.org.au/sites/default/files/documents/NMAS\%201\%20July\%202015. pdf $>$ (NMAS Approval Standards).

65 NMAS Practice Standards, s 1.2, above n 3.

66 See NMAS Practice Standards, above n 3, s 8.3 and the Revised NMAS documentation, Part I - Introduction, Application (citation omitted). Of particular relevance, are the subject-matter based standards developed for mediators in the family law area: see the 'obligations' imposed on Family Dispute Resolution Practitioners by the Family Law (Family Dispute Resolution Practitioners) Regulations 2008 (Cth).

67 LCA, Ethical Guidelines for Mediators, above n 61, s 1. See also Law Society of New South Wales, Guidelines for Legal Practitioners who act as Mediators, above n 62, s 2.1 .

68 Revised NMAS documentation, Part I - Introduction, Role of mediators in a mediation process.

69 NMAS Practice Standards, above n 3, s 2.2; LCA, Ethical Guidelines for Mediators, above n 61, s 1 . 
relationship between the mediator and the parties).$^{70}$ The duties are: a duty to exercise reasonable care and skill in the conduct of the mediation (that is, mediators owe the parties a duty of competence); a duty to maintain procedural fairness; a duty to avoid actual and potential conflicts of interest; a duty to maintain impartiality towards the parties; a duty to terminate the process in certain circumstances and a duty to maintain the confidentiality of anything said or done at the mediation). Mediators might also owe the parties and other affected persons a duty to ensure a fair outcome - this is a matter which is still open to debate. Each of these duties is discussed below.

\section{A A Duty of Competence}

The standards of conduct provide that mediators should be competent, that is, they should have the capacity to apply knowledge, skills and an ethical understanding and commitment in a range of enumerated areas, sufficient to satisfy the reasonable expectation of the parties. ${ }^{71}$ In reality, the scope of the duty of competence (and the tasks required to be performed to discharge that duty) depends on what the mediator perceives his or her specific role to be (for example, to improve the way the parties communicate, to facilitate settlement negotiations, to promote transformation of the parties and their relationship or to evaluate the parties' respective claims), which in turn depends on the model(s) of mediation favoured by the mediator. This, in turn, depends on the objective(s) and values prioritised by the mediator.

\section{B A Duty to Ensure Procedural Fairness}

Whatever model of mediation is chosen by the mediator, the duty of competence includes a duty to ensure procedural fairness. In scoping out the mediator's duty in relation to procedural matters, the NMAS Practice Standards speak to the mediator: ${ }^{72}$

(a) supporting self-determination, that is, assisting the participants 'to reach agreements freely, voluntarily, without undue influence and on the basis of informed consent'; ${ }^{73}$

(b) providing the parties with appropriate opportunities to speak and to be heard and to articulate their interests and concerns; ${ }^{74}$

(c) encouraging and supporting 'balanced negotiations'; ${ }^{75}$ and

70 For discussion of the possibility of mediator liability in equity, see Boulle, Mediation, 3rd ed, above n 16, 726-728.

71 See, for example, NMAS Practice Standards, above n 3, ss 8.1, 10.1. See also LCA, Ethical Guidelines for Mediators, above n 61, s 4.

72 NMAS Practice Standards, above n 3, s 7 which deals with procedural fairness and impartiality.

73 Ibid, s 7.4 .

74 Ibid, s 7.5 .

75 Ibid, s 7.7 . 
(d) encouraging the participants 'to assess any proposed agreements ... with reference to their long-term viability' taking into account the parties' interests and concerns. ${ }^{76}$

A mediator might be in breach of this provision if he or she continually interrupted one party and gave that party a short time within which to speak, as compared to the other party.

The NMAS Practice Standards impose an obligation on mediators to be alert to, and to manage, power imbalances and to take appropriate steps to ensure the safety and comfort of participants. ${ }^{77}$ The difficulty for mediators is to intervene to balance power and negotiations without negatively impacting the appearance of impartiality, a matter which is discussed in more depth shortly.

\section{A Duty to Disclose Potential and Actual Grounds of Bias or Conflicts of Interest}

Most standards of conduct require mediators to conduct mediation in an impartial manner. ${ }^{78}$ This requires, amongst other things, that a mediator identify and disclose to the participants any factor which creates a potential for, or actual, bias or conflict of interest 'before the mediation, or that emerge at any time during the process'. ${ }^{79} \mathrm{~A}$ mediator might have a conflict of interest if, for example, he or she had previously acted as a legal representative for one of the parties in another matter. A mediator is required to disclose this type of information. Once the required disclosure has been made, a mediator may still continue with the mediation if he or she has the consent of the participants and in addition, provided that 'in the mediator's view, the conflict would not impair his or her impartial conduct of the process'. ${ }^{80}$

\section{A Duty to be and to Remain Impartial}

Impartiality is a key attribute of mediators and this is reflected in most standards of conduct. For example, the NMAS Practice Standards provide that a mediator 'must conduct the mediation in a fair, equitable and impartial way, without favouritism or bias in act or omission' ${ }^{81}$ No further definition of impartial is provided in the NMAS Practice Standards. Some insight into the possible meaning of impartiality can be gleaned from leading scholars in the field, such as Boulle who takes it to mean 'an

$76 \quad$ Ibid, s 7.7.

77 Ibid, s 6.

78 See, for example, NMAS Practice Standards, above n 3, s 7.1; Model Standards of Conduct for Mediators, above n 63, s II.

79 NMAS Practice Standards, above n 3, ss 7.2, 8.2.

80 Ibid, s 7.3.

81 NMAS Practice Standards, above n 3, s 7.1. See also LCA, Ethical Guidelines for Mediators, above n 61, ss 1, 2; Law Society of New South Wales, Guidelines for Legal Practitioners who act as Mediators, above n 62, s 5.1. 
even-handedness, objectivity and fairness towards the parties during the mediation process'. ${ }^{82} \mathrm{~A}$ mediator might be in breach of this provision if he or she continually steered the conversation towards an outcome which favoured one party over the other.

Early definitions of mediation also commonly refer to the mediator as a neutral third party but in recent years, the concept of mediator neutrality has come under scrutiny (and the reference to neutrality has disappeared from some of the standards and definitions). ${ }^{83}$ There is growing recognition that mediators cannot be neutral if 'neutrality' is taken to refer to disinterest in the outcome of a dispute and absence of influence over the outcome. ${ }^{84}$

Several authors recommend a movement away from a binary construct of neutrality (as something that either does or does not exist) and urge instead that mediator neutrality be reconceptualised or reframed as a situated, contextual concept ${ }^{85}$ although authors vary slightly between themselves as to how it should be reframed. Douglas reframes it in such a way as to enable mediators to intervene to foster party selfdetermination; ${ }^{86}$ while Astor reframes it to strengthen the concept of consensuality. ${ }^{87}$ These efforts to reconceptualise neutrality seek to make it legitimate for mediators to intervene to deal with the parties' problematic power relations' ${ }^{88}$ and to 'ensure fair outcomes' ${ }^{89}$ - something which Astor maintains may involve some equalisation. ${ }^{90}$ Astor argues that such an approach 'provides for the inevitable situatedness of mediators' ${ }^{91}$ It also means that the propriety of an intervention can only be evaluated in the particular context in which it occurs. ${ }^{92}$

82 Boulle, Mediation, 3rd ed, above n 16, 73, 77.

83 When the NMAS Practice Standards were revised in July 2015, the word 'neutrality' was deleted from the list of ethical competences or understandings required by a mediator (see s 10.1(c)).

84 See the discussion by Susan Douglas, 'Neutrality in Mediation: A Study of Mediator Perceptions' (2008) 8(1) Queensland University of Technology Law and Justice Journal 139, 155.

85 See, for example, Hilary Astor, 'Mediator Neutrality: Making Sense of Theory and Practice' (2007) 16(2) Social \& Legal Studies 221, 221.

86 Douglas, above n 84, 155.

87 Astor prefers to reconstruct neutrality in terms of the core mediation value of consensuality which she argues is about enabling all the parties 'to have the maximum control possible given their context and situation': Astor, above $\mathrm{n} 85$, 234.

88 Tony Bogdanoski, 'The "Neutral" Mediator's Perennial Dilemma: to Intervene or Not to Intervene' (2009) 9(1) Queensland University of Technology Law and Justice Journal 26, 36. Indeed, Astor asserts that mediators have an obligation to deal with power relationships in mediation: Astor, above n 85, 236.

89 Bogdanoski, above n 88, 43.

90 Astor, above n 85, 236.

91 Ibid 221.

92 Bogdanoski, above n 88, 38. 
Still other commentators believe that the whole notion of neutrality is a 'fiction'. ${ }^{93}$ Coben asserts that the reality is 'the routine, but undisclosed mediator exercise of influence'. ${ }^{94}$ Mediators bring their own values and interests to mediation and to some extent they encourage outcomes consistent with those values and interests. ${ }^{95}$ Generally, the primary goal of mediators is to achieve agreement between the parties. ${ }^{96}$ They may be motivated in their attempts by concern for the parties or for third parties; by their desire for the outcome to conform to certain norms and standards; by concern for their reputation or by the need to secure remuneration and future business. ${ }^{97}$ Either way, all mediators (even those using less interventionist models) use a range of strategies to influence the content and outcome of mediations. They may, for example, use hypothetical questions to introduce ideas, create acceptable focal points for discussion, assist the parties to package offers and counter-offers and engage in conditional linked bargaining. They may create opportunities to explore some (favoured) options, but not others; and use time deadlines to force concessions and prevent further exploration of options.

As noted earlier, most standards of conduct prohibit mediators from coercing the parties to settle. ${ }^{98}$ However, the standards do not draw any clear dividing lines between what is, and what is not, 'coercion' and what is, and what is not, an appropriate intervention. The standards generally avoid referring to the specific interventions which mediators can make. Mediators may use a range of techniques which exert pressure to settle on the parties. Most techniques are subtle (for example, emphasising the mutual benefits to be obtained by agreement and stressing the possible negative consequences of failure to agree); others are more obvious (for example, indicating impatience or disapproval; using long silences; and holding lengthy sessions that facilitate compromise and wear the parties down). ${ }^{99}$ Mediators might be able to agree that some 'techniques' are coercive and inappropriate (for example, locking the parties in a room until they reach agreement). But they are unlikely to agree on a range of other techniques, for example, take silence - for how long can a mediator remain silent before crossing a line from appropriate pressure to settle to inappropriate coercion? The answer is likely to depend on the circumstances of the case.

93 James R Coben, 'Gollum, Meet Sméagol: A Schizophrenic Rumination on Mediator Values Beyond Self-determination and Neutrality' (2004) 5(2) Cardozo Journal of Conflict Resolution 65, 73.

94 Ibid 74.

95 Wolski, above n 16, 250. See also Susan S Silbey, 'Mediation Mythology' (1993) 9(4) Negotiation Journal 349, 351 who also refutes claims to mediator neutrality or disinterest.

96 Weckstein, above n 53, 510; Shapira, above n 15, 261.

97 See Wolski, above n 16, 250 for a discussion of possible mediator interests.

98 See, for example, NMAS Practice Standards, above n 3, ss 2.5, 7.4.

99 Wolski, above n 16, 251-254. 
The effectiveness of mediator strategies relies to a large degree on the mediator utilising various sources of power and influence. ${ }^{100}$ The mediator's most obvious source of power derives from his or her ability to control the process and procedure of mediation. As Shapira notes, '[c]ontrol over process is a powerful tool of influence'. ${ }^{101}$ The standards give mediators broad and explicit power over procedural matters. Most of the interventions made by mediators can be justified as process interventions. Yet many of these interventions have a profound effect on the substantive outcome of the mediation. Shapira concludes that mediators, despite their lack of 'formal power to impose an outcome on the parties ... have considerable influence on the parties, the process, and its outcome'. ${ }^{102}$

All mediators have the ability to influence the substance and outcome of mediations. They may also have an overriding ethical obligation to do so in some circumstances.

\section{E A (Possible) Duty to Ensure Fair Outcomes}

There is a long-standing debate on whether or not mediators ought to be responsible for ensuring fair mediated outcomes. There are two issues involved here for an outcome might be considered unfair to one or more of the parties or it might have negative (and unfair) consequences for third parties not present at the mediation.

Assuming the procedure used is fair and that the proposed outcome does not involve the commission of an offence or fraud, should a mediator intervene to protect a party against a manifestly unfair agreement?

The matter is still highly contentious ${ }^{103}$ in part because it begs the question of what is fair. Schuwerk asserts that the question of whether a mediator should remain completely impartial or should be 'free to intercede to some extent to protect one party - particularly if unrepresented - against a clearly unjust outcome, should be decided in favour of intervention'. ${ }^{104}$ Menkel-Meadow asserts that a lawyer mediator should decline to 'sanction' an agreement which the mediator has reason to believe would cause injustice to any party including third parties. ${ }^{105} \mathrm{On}$

100 See Wolski, above n 16, 250-251 and sources cited therein for discussion of mediator sources of power and influence. More recently, see Omer Shapira, 'Exploring the Concept of Power in Mediation: Mediators' Sources of Power and Influence Tactics' (2008-2009) 24(3) Ohio State Journal on Dispute Resolution 535, 541-558.

101 Shapira, above n 100, 556.

102 Shapira, above n 100, 568.

103 Macfarlane, above n 30, 52; Mary Anne Noone and Lola Akin Ojelabi, 'Ethical Challenges for Mediators around the Globe: An Australian Perspective' (2014) 45 Washington University Journal of Law and Policy 145, 179-182; Ellen Waldman and Lola Akin Ojelabi, 'Mediators and Substantive Justice: A View from Rawls' Original Position' (2016) 30(3) Ohio State Journal on Dispute Resolution 391.

104 Robert P Schuwerk, 'Reflections on Ethics and Mediation' (1997) 38(2) South Texas Law Review 757, 764.

105 Carrie Menkel-Meadow, 'Ethics and Professionalism in Non-Adversarial Lawyering' (1999-2000) 27 Florida State University Law Review 153, 167-168. 
the other hand, authors such as Bush and Stulberg take the view that it is not the mediator's job to guarantee a fair agreement, or any agreement at all; it is the mediator's job to guarantee the parties the fullest opportunity for self-determination and mutual acknowledgment.' ${ }^{106}$ If a party makes what appears to be a free and informed choice, he or she can settle for less than they are entitled to - in the name of self-determination.

As to the second issue, that is, of whether or not a mediator should intervene to protect the interests of unrepresented parties, the answer may depend in part on the subject matter of the dispute. Hobbs and Susskind suggest that mediators have duties to parties beyond those at the mediation table in family law and public interest disputes. ${ }^{107}$ Susskind argues that mediators of environmental disputes 'ought to accept responsibility for ensuring ... that agreements are as fair and stable as possible, and ... [that they] set constructive precedents'. ${ }^{108}$ In family law matters, an obligation to consider the interests of children is imposed on mediators (and legal representatives) by relevant legislation. ${ }^{109}$ Alison Taylor agrees that it is appropriate for mediators to 'suspend client self-determination' and intercede when parents agree to a course of action for their child which is contrary to law. ${ }^{110}$

Several authors take a more moderate approach on this issue. Hyman believes that a mediator should deal with matters of fairness and justice in mediation but only to a limited extent - by non-directive discussion of fairness and justice issues after which the parties are free to determine the final outcome. ${ }^{111} \mathrm{~A}$ similar view is expressed by Hughes who suggests that the mediator should assist the parties to assess any agreement they reach for its fairness and enforceability without the mediator taking responsibility for the content of the agreement. ${ }^{112}$ This appears to be the position adopted in relevant mediator standards, which impose upon mediators duties to help the parties reach a fair and equitable settlement (for example, by raising questions as to the fairness, equity and feasibility of proposed options for settlement) and to ensure consideration

106 Bush, above $\mathrm{n}$ 21, 272; Joseph B Stulberg, 'The Theory and Practice of Mediation: A Reply to Professor Susskind' (1981) 6(1) Vermont Law Review 85, 86-88.

107 Steven H Hobbs, 'Facilitative Ethics in Divorce Mediation: A Law and Process Approach' (1987-1988) 22(3) University of Richmond Law Review 325, 327, 339; Lawrence Susskind, 'Environmental Mediation and the Accountability Problem' (1981) 6(1) Vermont Law Review 1, 40-41.

108 Susskind, above n 107, 18.

109 In England and Wales and Australia, the law dictates that the children's welfare is paramount. See generally Lisa Webley, 'Divorce Solicitors and Ethical Approaches - The Best Interests of the Client and/or the Best Interests of the Family?' (2004) 7 Legal Ethics 231, 247.

110 Alison Taylor, 'Concepts of Neutrality in Family Mediation: Contexts, Ethics, Influence, and Transformative Process' (1997) 14 Mediation Quarterly 215, 222.

111 Jonathan M Hyman, 'Swimming in the Deep End: Dealing with Justice in Mediation' (2004-2005) 6 Cardozo Journal of Conflict Resolution 19, 44.

112 Patricia Hughes, 'Ethics in Mediation: Which Rules? Whose Rules?' (2001) 50 University of New Brunswick Law Journal 251, 259-260. 
of the interests of vulnerable parties and other affected and absent third persons - while leaving the parties to be responsible for the decision. ${ }^{113}$

\section{F A Duty to Terminate the Proceedings in Certain Circumstances}

The standards also recommend that mediators be alert to parties and advisers misusing mediation (for example, to delay other proceedings or to buy time to divert assets), or otherwise acting in bad faith. ${ }^{114}$ The NMAS Practice Standards and the LCA Ethical Guidelines for Mediators allow mediators to terminate the process if they consider that one or more of the parties is misusing the process, not participating in good faith or that mediation is no longer suitable or productive. ${ }^{115}$ The agreement of the parties is not required in these circumstances.

\section{G A Duty to Maintain the Confidentiality of Anything Said or Done at the Mediation}

The things said and done at mediation are generally considered to be confidential as against the outside world. ${ }^{116}$ An obligation of confidentiality may be imposed by the agreement to mediate in the case of private mediations or it might be imposed by applicable statute. ${ }^{117} \mathrm{It}$ is also included in some standards of conduct. ${ }^{118}$ For example, Standard V of the US Model Standards of Conduct for Mediators provides that '[a] mediator shall maintain the confidentiality of all information obtained by the mediator in mediation, unless otherwise agreed to by the parties or required by applicable law'. Curiously the NMAS Practice Standards do not seek to impose such a duty on mediators - they only require mediators to conform to the parties' agreement on this issue. ${ }^{119}$ Various exceptions to confidentiality are usually provided, for instance, as may be the case in relation to fraud or an offence committed during the mediation. ${ }^{120}$ A mediator might also have a duty to maintain the confidentiality of anything said or done in a separate session with a party, such that the mediator cannot disclose the information to the other party without the consent of the disclosing

113 NMAS Practice Standards, above n 3, s 8.4; Model Standards of Conduct for Mediators, above n 63, s VI(A).

114 Ibid, s 5.1 .

115 Ibid. See also LCA, Ethical Guidelines for Mediators, above n 61, s 6.

116 Melvin A Rubin and Brian F Spector, 'Ethical Conundrums for the 21st Century Lawyer/Mediator “Toto, I've a Feeling We're Not in Kansas Any More"' (2008) 2 American Journal of Mediation 73.

117 See, for instance, the provisions of the Civil Proceedings Act 2011 (Qld).

118 See, for instance, LCA, Ethical Guidelines for Mediators, above n 61, s 5.

119 NMAS Practice Standards, above n 3, s 9.1.

120 The limitations will be set out in the agreement to mediate (if there is one) or the statute pursuant to which the mediation takes place and the standards of conduct. See the LCA, Ethical Guidelines for Mediators, above n 61, s 5 and NMAS Practice Standards, above n 3, s 9.1. 
party. However, some mediators reserve the right to determine whether or not to disclose information revealed in separate sessions. In respect of this matter, what is important is that the parties are made aware of the mediator's preferences and that the mediator then meets the expectations of the parties.

The principles articulated in relevant mediator standards may conflict. Such a conflict may arise, for instance, if a mediator considers that one party cannot make a fully informed decision because the other party is withholding material information known to the mediator because it was disclosed in a separate session (the duty of confidentiality owed to one party potentially conflicts with the duty to ensure procedural fairness and possibly, with a duty to ensure outcome fairness). When there is a conflict of values, mediators often must choose between contradictory courses of action. Decision-making in circumstances such as this will involve an exercise of discretion on the part of the mediator.

\section{Conclusion: The Exercise of Discretion by Mediators}

When mediators are confronted with an ethical dilemma, such that the principles or values underlying mediation are in conflict, and the mediator has to make a choice as to which value(s) should be given priority, he or she can look to the relevant standards and guidelines discussed in this article but they are unlikely to find specific answers there. The standards of conduct for mediators, as for lawyers, are stated in general terms. This is not necessarily a bad thing. ${ }^{121}$ A number of commentators, such as Pou, favour broad codes which allow mediators flexibility to use intuition, judgment, and proficiency'; ${ }^{122}$ codes which will allow mediators to be 'reflective rather than prescriptive'. ${ }^{123}$ He suggests that mediator ethical expectations 'will, and should, depend on case-specific factors' ${ }^{124}$ including the location of a particular mediation process (for example, whether it is court-annexed, agency-based, or purely private); the substantive nature of the dispute (for example, whether it be family, commercial, neighbourhood); 'the sophistication level of the parties, or their explicit expectations as to how a mediator will assist them' ${ }^{\prime 25}$ (for example, by improving the communication environment, changing the dynamics of negotiation, and/ or providing the parties with advice); and the goal of the mediation process and which of the various styles or approaches a mediator adopts (for example, whether facilitative, evaluative or transformative) ${ }^{126}$ In essence, Pou's view is 'that variations in ADR settings do and should, have an

121 Charles Pou Jr, "Embracing Limbo": Thinking About Rethinking Dispute Resolution Ethics' (2003-2004) 108 Pennsylvania State Law Review 199, 202.

122 Ibid 211.

123 Ibid 222.

124 Ibid 209.

125 Ibid.

126 Ibid. 
impact on expectations about what mediator behaviour is appropriate (or ethical or unethical)'. ${ }^{127}$

Several authors argue that existing mediator ethics need to be reassessed to allow for more responsive, reflexive conduct by mediators. For example, Honoroff and Opotow criticise the current approach to the formulation of mediator ethics. It is their view that current ethical mandates have been derived from a particular conception of the mediator's role - a conception that they call a 'top down' approach. Honoroff and Opotow suggest instead that a 'bottom-up' approach be used (an approach they refer to as 'grounded ethics'), ${ }^{128}$ allowing mediators to make ethical judgments that are more contextualised, 'guided by the particulars, the substance, and the context of the dispute'. ${ }^{29}$

Macfarlane also proposes that we should adopt new 'context-responsive' ways of thinking about mediation ethics. ${ }^{130}$ She calls for the adoption of a 'reflective-practice' approach as an alternative or complementary vehicle to codes of conduct for mediators, a model which requires practitioners 'to develop a capacity for reflective self-analysis of their effectiveness in practice situations'. ${ }^{131}$ In essence, ' $[\mathrm{t}]$ he outcomes of ethical judgments by mediators must be supported by the reasoned and contextual perspective of that mediator and that mediation'. ${ }^{132}$

In these circumstances, it is important that we instil in mediators (through training, mentoring programs and peer interaction) an awareness of ethics and an ability to adopt an ethical evaluation process into which important variables can be factored. This article has considered three factors which a mediator might take into account: his or her conception of mediation's important objectives and values; the mediator's preferred dominant approach to mediation, and the standards of conduct to which the mediator is subject. Inevitably, different practitioners may choose a different course of action when confronted with the same or similar ethical dilemmas. According to the relevant literature, that does not matter. ${ }^{133}$ No model of ethical decision-making will:

[G]uarantee the same response by different people in similar circumstances, but it should represent a guarantee that a comprehensive and responsive approach will be undertaken before deciding, and that consequently, a framework for consultation and collaborative dialogue about ethical matters is more possible. ${ }^{134}$

It is the evaluation process which is important. Although mediators may arrive at different conclusions, each of them should have good reasons for

127 Ibid 201 (citations omitted).

128 Brad Honoroff and Susan Opotow, 'Mediation Ethics: A Grounded Approach' (2007) 23 Negotiation Journal 155, 166.

129 Ibid 168.

130 Macfarlane, above n 30, 65, 73, 70.

131 Ibid 72.

132 Ibid 71.

133 Preston, above n 5, 77.

134 Ibid. 
what they do and the actions they take. They should be able to justify the consequences of their actions.

It is only relatively recently that the mediation community has begun to consider - in a scholarly manner - the ethics of mediation. There are many important questions that require our attention as we move forward. They include:

(1) How effective in other areas of decision-making are long lists of 'factors' such as that presented in this article?

(2) What lessons, if any, can be learned from other professions about the concept, and limits, of self-determination?

(3) For each of the arguably hundreds of interventions that mediators make, can we construct a table of gradations of responses? Is there a core of solid 'thou shall and thou shall not' responses?'135

(4) What is the most effective way in which to regulate the behaviour of mediators? What can standards of conduct achieve? Can standards be enforced and if so, by whom and how?

(5) If standards are not effective in regulating mediator behaviour, should we rely more on education? Can ethics be taught and if so, how and by whom?

135 I am indebted to an anonymous reviewer for this idea and this phrase. 